\title{
Balkanologie
}

Balkanologie Revue d'études pluridisciplinaires

Vol. VI, $n^{\circ}$ 1-2 | 2002

Volume VI Numéro 1-2

\section{Mali Zvornik}

\section{Bernard Lory}

\section{OpenEdition}

Journals

Édition électronique

URL : http://journals.openedition.org/balkanologie/436

DOI : $10.4000 /$ balkanologie.436

ISSN : 1965-0582

\section{Éditeur}

Association française d'études sur les Balkans (Afebalk)

\section{Édition imprimée}

Date de publication : 1 décembre 2002

Pagination : 15-18

ISSN : 1279-7952

\section{Référence électronique}

Bernard Lory, « Mali Zvornik », Balkanologie [En ligne], Vol. VI, nº 1-2 | 2002, mis en ligne le 03 février 2009, consulté le 17 décembre 2020. URL : http://journals.openedition.org/balkanologie/436 ; DOI https://doi.org/10.4000/balkanologie.436 


\title{
MALI ZVORNIK
}

\author{
Bernard Lory*
}

Les débuts de l'autonomie de la Serbie baignent dans un grand flou juridique. Un terme fut mis à la Seconde Insurrection serbe en 1815 par un simple accord verbal entre le beylerbey de Roumélie Marașl Ali pacha et Miloš Obrenović. Ce dernier se voyait reconnu comme oberknez, c'est à dire comme interlocuteur privilégié du pouvoir ottoman et porte-parole de la population chrétienne serbe. Une relative autonomie interne était accordée à celle-ci dans le cadre du pachalik de Belgrade.

Il fallut beaucoup de doigté, de ruse et souvent de mauvaise foi à Miloš Obrenović pour consolider ses fragiles positions. Dès 1820, pourtant, il souleva la question de l'étendue territoriale de sa juridiction. Il argumentait ses prétentions en s'appuyant sur le seul document international évoquant l'autonomie de la Serbie, à savoir le Traité de Bucarest, signé le 28 mai 1812 entre l'Empire ottoman et la Russie, alors pressée de se dégager de la zone danubienne pour parer à la menace napoléonienne. Les Ottomans s'y étaient engagés à amnistier les insurgés serbes et à rétablir leur autonomie interne. L'année suivante, pourtant, la Première Insurrection serbe (menée par Karadjordje Petrović) était écrasée.

En 1820, donc, s'appuyant sur ce traité resté lettre morte, Miloš Obrenović fit valoir que le territoire désigné en 1812 était plus vaste que le seul pachalik de Belgrade et réclama l'extension de l'autonomie serbe à l'ensemble des territoires contrôlés par l'insurrection huit ans plus tôt, soit à six nahiye situés à l'est, au sud et à l'ouest. Le nahiye de Loznica, correspondant aux terroirs de Jadar et Radjevina, relevait du pachalik de Zvornik, centré en Bosnie, mais qui débordait sur la rive droite de la Drina de façon significative. Le principal axe de communication nord-sud dans la partie occidentale de la Serbie était donc soumis au contrôle ottoman. 
Soulevée en 1820 , la question des six nahiye fut prise en compte par la diplomatie russe dans la Convention d'Akkerman (7 octobre 1826) et surtout par le Traité d'Andrinople (14 septembre 1829). En conséquence, le pouvoir ottoman reconnut l'autonomie de la principaute de Serbie par deux hatt-i șerif en 1830 et 1833 , ainsi que l'extension de celle-ci aux six nahiye. Ces dernières étaient assez mal définies et une commission russo-turque fut chargée, à la fin de 1830, d'en déterminer les limites exactes. En raison de l'agitation en Bosnie menée par Husejin Kapetan Gradaščević, cette commission mixte s'abstint prudemment de visiter les bords de la Drina.

Après le problème de la délimitation venait celui du départ de la population "turque" des six nahiye. Le terme "turc" désigne à l'époque toute population musulmane, sans distinction de langue ou d'origine ethnique ; les "Turcs" de la rive droite de la Drina étaient bien évidemment slavophones et autochtones. La convention de 1830 stipulait que le Sultan garderait six forteresses (Belgrade, Šabac, Smederevo, Fethislam/Kladovo, Soko et Užice) et qu'à côté des garnisons, la population citadine musulmane pourrait y demeurer. Partout ailleurs, elle devrait vendre ses biens et quitter le territoire de la Serbie autonome. Cette évacuation devait s'effectuer dans un délai d'un an aux termes du hatt-i șerif de 1830 , mais, suite à de nombreuses difficultés pratiques, ce délai fut prolongé de cinq ans par le hatt-i șerif de 1833 , soit jusqu'en décembre 1838 . Si le départ des musulmans de la vallée de la Morava, où ils étaient peu nombreux et citadins, se fit rapidement en 1833 , ceux de la vallée de la Drina suscitèrent des difficultés.

Il s'agissait d'environ 8000 paysans re'aya, répartis sur 37 villages. Loin d'être une population isolée, ils s'appuyaient sur la masse compacte de leurs coreligionnaires bosniaques, sur la rive gauche de la Drina. Ces derniers venaient de connaitre une période d'effervescence insurrectionnelle, sous Husejin Kapetan Gradaščević, et nourrissaient de sourds ressentiments envers le pouvoir du Sultan.

En mai 1834, Miloš Obrenović fit établir un cordon militaire tout au long de la Drina, puis, en juillet 1834 , commença la prise de possession des villages musulmans. Ceux de la région de Loznica et de Lešnica se laissèrent convaincre de vendre leurs biens. Dans celle de Soko, en revanche, quatre villages qui résistaient furent incendiés et leur population se réfugia dans la forteresse. La Porte protesta, mais Miloš Obrenović sut l'apaiser par des bakchichs judicieusement répartis. Un seul point litigieux resta en suspens, celui des deux villages de Mali Zvornik et de Sakar (155 maisons en tout), situés sur les bords mêmes de la Drina, et sous la protection des canons de la forteresse de Zvornik sur l'autre rive, si bien que les forces serbes n'avaient pas osé s'y aventurer.

Une commission mixte, envoyée en novembre 1834, tomba dans une embuscade. Les commissaires serbes parvinrent à s'échapper, mais leurs collègues ottomans furent malmenés et délestés de l'importante somme de $10000 \mathrm{du}$ - 


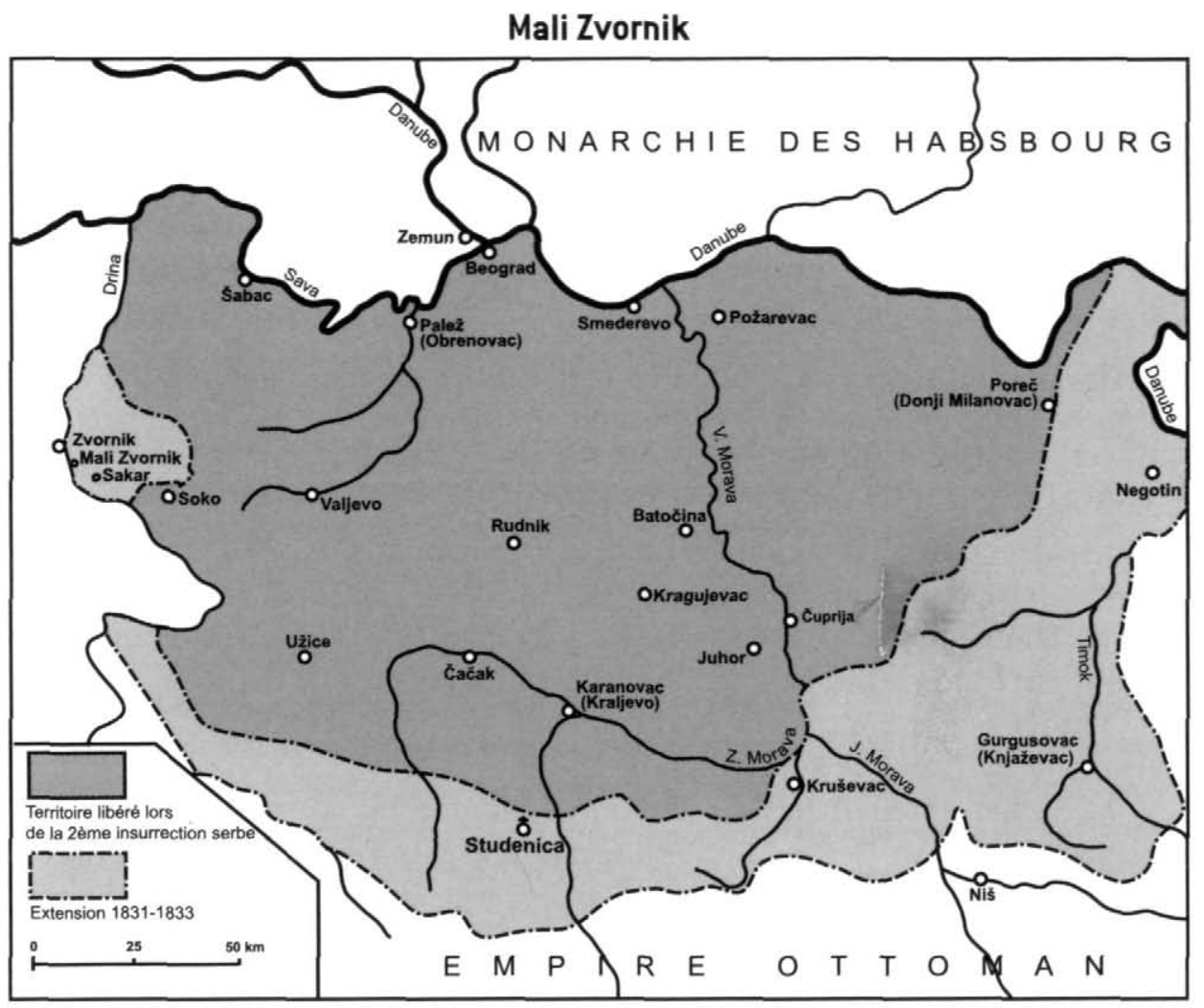

cats, destinée au rachat des biens musulmans : ils furent relâchés le lendemain, à demi-nus. Cette provocation de la part des Bosniaques de Mahmud pacha de Zvornik entraîna des pourparlers supplémentaires. Tandis que les villages évacués par les musulmans étaient occupés par des chrétiens dès 1835 , Mali Zvornik et Sakar gardèrent leurs habitants au-delà du délai de décembre 1838. Les efforts diplomatiques de Miloš Obrenović pour les obtenir restèrent vains. Sous le règne d'Alexandre Karadjordjević (1842-1859) la Serbie s'abstint de toute revendication envers la Porte.

La petite enclave de Mali Zvornik, qui mesurait trois heures de marche en longueur pour une en largeur (soit environ $40 \mathrm{~km}^{2}$ ), n'en restait pas moins une épine désagréable au pied de la Serbie. Elle rendait la circulation le long de la Drina hasardeuse (le célèbre voyageur Felix Kanitz fut refoulé) et constituait une tête de pont ottomane sur la rive droite potentiellement dangereuse en cas de conflit. Mihajlo Obrenović, lors de son second règne (1860-1868) parvint à se débarrasser des deux forteresses de Soko et Užice en 1862, puis des quatre autres, dont celle de Belgrade, en 1867.

$\mathrm{Ne}$ restait donc que l'enclave de Mali Zvornik comme anomalie territoriale. La régence qui suivit l'assassinat de Mihajlo se trouva dans une situation 
internationale délicate, en mauvais termes à la fois avec la Russie et avec l'Autriche-Hongrie. Limitée dans sa politique nationale, elle prit à cœur la question toute symbolique de Mali Zvornik et enjoignit son représentant permanent auprès de la Porte (kapu kehaya) de la mettre obstinément sur le tapis, lors de chacune de ses visites hebdomadaires. Cette politique de harcèlement diplomatique était assez puérile. Non seulement elle n'eut aucun succès, mais elle focalisa l'opinion internationale sur un litige mineur.

Lorsque s'ouvrit la grande crise d'Orient (1875-1878) et que la diplomatie des Grandes Puissances s'appliqua à régler les problèmes balkaniques, on vit surgir ce point de détail sur le tapis vert, en même temps que les enjeux majeurs. La question de Mali Zvornik fut très sérieusement abordée par la Conférence des Ambassadeurs à Constantinople en décembre 1876 (elle fit même l'objet d'une escarmouche entre le Président du Conseil d'Etat ottoman, Ethem pacha, et l'ambassadeur de Russie Ignatiev) ; on la retrouve dans l'article 3 du Traité préliminaire de San Stefano ( 3 mars 1878), dans le Memorandum adressé par le gouvernement serbe aux Grandes Puissances le 24 juin 1878 ; elle fut abordée par le Congrès de Berlin, lors de la séance du 8 juillet, et figure à l'article 36 du Traité de Berlin (13 juillet 1878).

La Serbie obtenait de la sorte enfin satisfaction. Victoire ? Loin de là, puisque le Traité de Berlin lui interdisait tout espoir d'extension territoriale et même d'action nationale en Bosnie-Herzégovine, ce qui avait été son objectif politique principal au cours des trente années précédentes. Face à Mali Zvornik enfin recouvré, sur la rive gauche de la Drina, les canons étaient désormais austro-hongrois...

\section{SOURCES UTILISÉES :}

Documents diplomatiques. Affaires d'Orient 1875-1876-1877, Paris, 1877 (Livre jaune français).

Gravier (Gaston), Les frontières historiques de la Serbie, Paris, 1919.

Srbija 1878. Dokumenti, Belgrade, 1878.

Istorija srpskog naroda (Histoire du peuple serbe), t. V1, Belgrade, 1981.

Ljušić (Radoš), Kneżevina Srbija (1830-1839) (La Principauté de Serbie 1830-1839), Belgrade, 1986 (surtout pp. 314-327). 